\title{
Impact of climate change on agriculture and water resources of Pakistan: A review
}

\author{
Talha Mehmood $^{1 *}$, Zia-Ul-Haq ${ }^{1}$, Saad Mahmood ${ }^{2}$, Sohail Raza Haidree ${ }^{1}$, \\ Hamza Muneer Asam ${ }^{1}$ and Abdul Qadeer ${ }^{1}$ \\ 1. Faculty of Agricultural Engineering and Technology, PMAS-Arid Agriculture University, Rawalpindi-Pakistan \\ 2. Faculty of Crop and Food Sciences, PMAS-Arid Agriculture University, Rawalpindi-Pakistan \\ *Corresponding author's email: chtalha94@gmail.com \\ Citation \\ Talha Mehmood, Zia-Ul-Haq, Saad Mahmood, Sohail Raza Haidree, Hamza Muneer Asam and Abdul Qadeer. \\ Impact of climate change on agriculture and water resources of Pakistan: A review. Pure and Applied Biology. Vol. \\ 10, Issue 1, pp152-159. http://dx.doi.org/10.19045/bspab.2021.100017
}

\begin{tabular}{llll}
\hline \hline Received: 19/05/2020 & Revised: 05/08/2020 & Accepted: 13/08/2020 & Online First: 17/09/2020
\end{tabular}

\section{Abstract}

Water sustains life on earth for sustainable development. Judicious management of water resource has emerged as a key challenge of current century. Fresh water is the most vulnerable resource and is prone to effects of changing climate. It may cause serious effects on the intensity, frequency and distribution of rainfall patterns on temporal and spatial scales; enhance melting of glaciers and increase number and severity of floods and droughts. The Indus River, a major water resource of South Asia, has emerged from the Himalayas and the Tibetan Plateau. Global average temperatures have been rising, consequently human activities have changed the composition of the atmosphere. In the recent past, world climate change had a substantial effect on the environment of high mountain: snow, glaciers are especially prone to variations in atmosphere. Among various climatic factors, precipitation plays a key role in management of natural resource, irrigation scheduling and hydrological modeling etc. Knowledge of temporal and spatial occurrence of precipitation is also crucial to study impact of climate change on various systems. Pakistan's agriculture growth depends mainly on irrigation, which produces over ninety percent of the country wheat, mostly pulses and nearly all of other important crops. Experts proposed resolutions for both demand and supply: new dams construction and other infrastructure, improved institutions governing water allocation, improved water productivity in agriculture and use. Changes in climate affects agriculture productivity, forestry and marine life, tropical cyclone and water sector.

Keywords: Agriculture; Climate change; Food security; Management; Water resources Introduction

Water, a commodity that supports life on the earth, is a key component of sustainable development. Renewable freshwater supplies are scarce in most developing countries. The nations endowed with pure water supplies have more economic benefits than others. Irrigation absorbs almost $80 \%$ of the total water supplies available in Asia. Asia accounts for seventy nine percent i.e. $370 \mathrm{M}$ ha, more than Europe and North America seven percent each, of all 
annualized irrigated areas. Approximately half of the world irrigation area is located in 6 Asian countries including India $(21.7 \%$ of the total world irrigated area), China $19.4 \%$, Pakistan $6.6 \%$, Iran $2.8 \%$, Indonesia $1.8 \%$ and Thailand $1.7 \%$ [1].

One of the key challenges of the $21^{\text {st }}$ century is the judicious management of agricultural land and water resources. Water and land are finite resources, but there is growing strong competition from others. Agricultural sector is the largest that consumed water resources, accounting for over seventy percent of the global fresh water diverted from rivers and reservoirs, although it is as high as $90 \%$ in Asia and the Pacific region [2].

\section{Impact of climate change on water resources}

Fresh water supplies are the most fragile and the changing climate can have a strong impact. There is ample evidence to support this claim by observational records as well as weather forecasts. The number and intensity of highly climatic events is expected to increase over the years [3]. This can cause severe impacts on the duration, frequency and distribution of rainfall spells on temporal and spatial scales; intensify glacier melting and increase the number and severity of floods and droughts. Potential direct effects of climate change include highly variable patterns of seasonal inflows to water supplies, water shortages for irrigation, inadequate groundwater recharge and rising sea levels, combined with significant decreases in water availability per person due to ever-increasing population, may have serious impact for water resources management.

Agro-based economy of Pakistan, heavily relies on Indus irrigation system. The Indus River has risen from the Tibetan Plateau and Himalayas as one of South Asia's major water carriers. As the river comes out of the mountains, it has a managed storage at Tarbela. The first largest structure constructed on the Indus River is the Tarbela that contributes its flow to the Indus Basin Irrigation System for irrigating Punjab and Sindh (Pakistan Provinces), the country's leading agricultural products producer. Tarbela inflow is estimated at point Besham Qila (Indus Basin Area of Besham = 2,01,388 $\mathrm{km}^{2}$ ), located at approximately eighty $\mathrm{km}$ of Tarbela upstream, with an average annual flow rate of $2,410 \mathrm{~m}^{3} / \mathrm{s}$ as per Surface Water Hydrology Project (SWHP) flow records from year 1969-2008. Tarbela reservoir downstream catchment area is termed as Upper Indus Basin (UIB) resulting from snow and glacier melting, contributes most of the influx to the Indus River through large mountains.

Tarbela reservoir management is largely dependent on inflow in the summer provided by Karakoram Range glacier and snow fed channels. The snow availability on mountains has a strong impact on the moisture deposited on the soil and usable for potential runoff [4]. In the UIB high-altitude sub-catchments, water runoff during summer often covered with permanent glaciers and snow pack, is highly associated with mean temperature in summer [5]. There is relatively higher runoff catchment in Hunza River located at Dainyor Bridge at the center of Karakoram where cryosphere contribute the major portion of flow. In the Indus catchment at Partab Bridge station, it approximately doubles the runoff level along with the Gilgit River. In these subcatchments, climate change will directly impact in flow of Indus irrigation system.

The steady rise in greenhouse gas emissions has contributed to global warming, and by the completion of current century substantial variations are predicted in the future climate. Global average temperatures have risen, and human activities have significantly changed the composition of the atmosphere so that we can now say with confidence that the environment will continue to change. In 
addition to the projected future temperature increase of $1.8-4.0{ }^{\circ} \mathrm{C}$ (IPCC AR4) by the end of 2100, changes in atmospheric and oceanic circulation and the hydrological cycle will result in large increases in the number and severity of extreme climatic events such as drought, floods and cyclones; rapid melting of world glaciers and ice sheets including polar ice; The bad impact of change in climate of developing countries like Pakistan, where climate change could threaten water and food security, will be particularly large.

Climate change in the world has had a substantial effect on the environment of high mountains in recent decades: snow, glaciers, due to their proximity to melting conditions, are in particular prone to changes in atmospheric conditions. In fact, one of the most clearly observable effects of temperature increase could be shifts in snowfall events and related effects on highmountain system physical conditions. This is also one of the main reasons for many years of using glacier measurements for tracking the climate system [6]. The rise in temperature recorded from the past several decades is commonly correlated with hydrological cycle changes such as: rising atmospheric water vapor; evolving patterns of precipitation, frequency and extreme events; widespread snow and ice melting; and changes in soil moisture and runoff. It is also possible that the predicted global temperatures will alter the hydrological cycle in ways which have a significant effect on the supply of water resources and improvements in water quality. Predicting future changes in weather patterns at regional level or ascertaining the real climate change impact on water resources is actually too much difficult.

Over the past decades, the effects of change in climate have become increasingly evident [7]. In low-income nations, climate change forecasts indicate a more volatile climate with higher risks [8, 9]. Pakistan is the highly vulnerable countries to climate change, with its mainly arid geographical profile and scarcity of resources [10]. The nation is already witnessing a rise in the number and intensity of weather events such as droughts, extreme temperatures, acute water shortages, flooding in some regions and enhanced pest and disease outbreaks. According to the Global Climate Change Vulnerability Index (CCVI), in 2009-2010, Pakistan ranked the $16^{\text {th }}$ most vulnerable country during 2010-2011 [11]. Several examples of more regular climate-related effects in Pakistan are the successive floods 2010 to 2014 and the severe drought that lasted from 1999 to 2003.

Due to changes in the levels of ambient greenhouse gases climate change has serious impacts on sustainable development of society and resources management. General Circulation Models (GCMs) provides a valuable overview for current climate situations and for futures predictions about climate changes in the world, their adjustment on different regional or local natural and controlled systems for climate change impact assessment is important to question for resolution of course [12-17].

Among various climatic variables, precipitation is important for many features such as farm management, irrigation planning, natural resource management, ecosystem modeling and hydrological modeling. It is important to know its temporal and spatial distribution for conducting study on climate change effects on various systems [18].

\section{Impact of climate change on agriculture}

Agriculture growth in Pakistan is heavily relying on irrigation, which accounts for over $90 \%$ of country wheat, mostly pulses and almost all other important crops [19]. Pasture irrigation contributed mainly for milk production and a major part of meat feeds $[19,20,21]$. Nevertheless, supply of 
water per capita has decrease with the growing population, groundwater is being overused, and salinity in general threatens water quality $[22,23]$. Future provisions to increase food platforms should be considered without more water sources and water should be used in less quantity [23]. All researchers agreed that water shortage problems should be properly resolved and find proper solutions that balance both demand and supply: Fresh reservoirs (although not preferred by Kugelman) and other such projects, increased water production in agriculture, and improved water distribution institutions [22-24].

Climate change is also projected to have an impact on production of food and food safety, both these are due to potential changes in the extent and irrigation water timing and direct impacts on yield of crop because of variations in temperature. There is unavailability about potential in the Indus Basin for water availability, with the forecasts that is based on different climatic models suggesting decreases and increase in the rainfalls, with somewhat higher likelihood of water availability till 2050 [2528]. Nevertheless, Laghari et al. [29] indicate that water availability might be increase in the small duration because of glaciers melting, there will be a significant reduction in availability by 2046-2065. Snow and ice hydrology will be affected due to variations in temperature, although it is projected that the impact on river flow volumes will be within current changes [28]. The variations in trends of rainfall and glaciers and snow melting might cause changes in flow rate. Archer et al. [30] indicated that data maintain contradictory as whether climate variations may have a good or bad effects on resources of water, while proposed that it may play a minor part than the other variables, like decreased in capacity because of dam sedimentation, increasing groundwater use and more economic development and population growth [25].

In view of its potential environmental implications for water scarce countries, the problem of climate change has arisen very vigorously on a global scale over the past two decades. In many regions around the world, steadily rise in temperatures and their impacts on the cryosphere and precipitation are visible. There is evidence that Pakistan has a great extent of variations in climatic that are occurred in the past in India northwest. Spatial changes in rainfall patterns were the major component of weather variability, along with changes in the region's general atmospheric circulation [31]. Changes in rainfall patterns have a direct effect on the energy, agriculture and disaster management. Pakistan is vulnerable to a lot of naturally occurring disasters viz., floods, cyclones, heavy rainfall, droughts and earthquakes, according to the Task Force on Climate Change (2010) report in Pakistan. The occurrence, frequency and intensity of extreme climatic events has increased over the past few decades: about $40 \%$ of Pakistan's people are very vulnerable to many disasters that occur with changes in rainfall trend, hurricanes, droughts and floods $[32,33]$.

The variations in rainfall pattern are increasing geographically, annually and across seasons in Asia in recent past years. There have also been decreasing trends in the amount of rainfall along arid plains and coastal areas of Pakistan [3]. Pakistan Meteorological Department indicated that many areas of Pakistan are experiencing hot climate. Humid conditions prevail in the north, however, over a small area. Sindh, major portion of Baluchistan, most regions of Punjab and Northern Areas central regions receive fewer than $250 \mathrm{~mm}$ rainfall. Wheat is the staple food of masses, grown almost throughout the country under diverse climatic conditions in Pakistan. The inland 
regions becomes as warm as $52^{\circ} \mathrm{C}$ while the mountain temperature drops well below the freezing point. Major portion of central and southern Pakistan, considered as the country's granary, are arid, while climate in the northern parts of the country is humid, with the exception of the dry extreme northern mountains [34]. Such regions have various geographical aspects that contribute in particular weather condition.

The country's wheat production has grown for the past four decades owing to green revolution. Nevertheless, there are growing concerns about the potential for abiotic and biotic stresses to strain sustainable productivity. Important factors among abiotic stresses is the climate change that threaten food security in both Pakistan and South Asia. Therefore, food security will be top agenda item in the near future in Asian countries, owing to population growth and have indirect and direct impacts on climate changes [35].

When average temperature increases up to $2.5 \%$, heat stress will limit wheat yield up to $60 \%$ [36]. Agriculture manly depends on climate conditions (light, heat, water) and implies a major impact on crop production due to climate changes [37-39]. Climate change in some parts can result in extended dry spells or very extreme heat waves, causing serious harm to plant growth by decreasing moisture $[35,40]$. In addition to increasing demand of water for agricultural crops on account of enhanced evapotranspiration, climate change will adversely impact the supply of water for crops [17]. It is well documented that water stress tends to increase the positive effects of the plant to increased $\mathrm{CO}_{2}$ relative to the conditions of the well water $[41,42]$. The country's arid zone is facing acute water shortage due to recent climatic change that has greatly impacted human life, biodiversity, and socio-economic activities. From a national and zonal aspect, recognizing the future climate change effects is therefore of utmost importance [34].

\section{Potential impacts of climate change}

The region's predicted climate variations include improving monsoon occurrence, increasing surface temperature of the earth and increasing the intensity and increased in the events of rainfall. The consequences associated with the environment will also result in rise in sea levels. These variations could have major effects on the habitats and biodiversity of the country; water resources and hydrology; agriculture, forestry, fisheries, coastal lands and mountains and human settlement and their health.

\section{Forestry and marine life}

The impacts on mangrove forests are commencing. Pakistan, the less impacted by increase in sea level and it resulted in damage of mangrove forests that are the major food and fuel wood source for breeding site and local residents for $90 \%$ of Pakistan main exporter of fisheries. Agriculture is in particularly important for climate-prone crops like rice, other grains and cereals, vegetables and spices.

\section{Agricultural productivity}

Agricultural productivity is likely to suffer adversely due to increased temperature, flood, and drought conditions etc. As a result, many countries in the region would be threatened with food security. Due to temperature variations in water, productivity in aquaculture is also likely to affect remarkable changes. The rise in sea level will cause the vast Asian coastline's large tracts to submerge, resulting in a depression of vast sandy beaches.

\section{Tropical cyclones can intensify}

When combine with the rise in sea level, it may result in an increased danger of loss of property and life in cyclone-prone, like Southeast Sindh, coastal low-lying areas. Warmer weather conditions will increase the potential for increased incidence of vectorborne diseases e.g. dengue fever and malaria 
due to heat and infection. Resultantly changes in land use and population pressure, changes in climate will also intensify the biodiversity dangers.

\section{Water sector}

It is pertinent to mention that agriculture and water sectors will be very vulnerable to change in climate. Pure water supply is predicted to be more dangerous for climate change. Although intensity and number of floods in river deltas would eventually increases. Extreme water stress can occur in the semi-arid and arid areas.

\section{Conclusion}

Debate on world water shortage and food security has deepened in recent times, owing to continuously shrinking resources of fresh water in most of the areas. For arid, semiarid and sub-humid areas, elevated temperatures have adversely impacted yield. Consequently, the economy of agro-based countries like Pakistan is at stake. It is high time to take care of all factors that are contributing to such a disaster. Improving present conservation practices and water use efficiency both in irrigated and rainfed farming is imperative to future economic and agricultural growth. Stopping of deforestation and planting of trees may be enhanced to improve the constantly deteriorating situation. All stake holders should pay heed to minimize the risk and join hands to improve the climate of the region.

\section{Authors' contributions}

All authors contributed in the preparation of manuscript.

\section{References}

1. FAO (2001). FAO (Food and Agriculture Organization) STAT agriculture data. http://apps.fao.org/.

2. Barker R \& Molle F (2005). Evolution of irrigation in South and Southeast Asia. Comprehensive Assessment Research Report 5, International Water
Management Institute (IWMI), Colombo, Sri Lanka.

3. IPCC (2007). Fourth Assessment Report, Executive Summary, WGI.

4. Maurer EP, Rhoads JD, Dubayah RO \& Lettenmaier DP (2003). Evaluation of the snow-covered area data product from MODIS. Hydrol Process 17(1): 59-71.

5. Archer D (2003). Contrasting hydrological regimes in the Upper Indus Basin. J Hydrol 274: 198-210.

6. Haberli W (1990). Glacier and permafrost signals of 20th century warming. Annals of Glaciol 14: 99-101.

7. Patt AG \& Schröter D (2008). Perceptions of climate risk in Mozambique: implications for the success of adaptation strategies. Glob Environ Chang 18: 458-467.

8. Easterling DR, Evans J, Groisman PY, Karl T, Kunkel KE \& Ambenje P (2000). Observed variability and trends in extreme climate events: a brief review. Bull Am Meteorol Soc 81: 417425.

9. McCarthy JJ (2001). Climate change 2001 In: Impacts, adaptation, and vulnerability: contribution of working group II to the third assessment report of the Intergovernmental Panel on Climate Change. Cambridge university press, Cambridge.

10. Schilling J, Vivekananda J, Khan MA \& Pandey N (2013). Vulnerability to environmental risks and effects on community resilience in mid-west Nepal and south-east Pakistan. Environ Nat Resour Res 3: 27-45.

11. Khan JA \& Fee L (2014). Cities and climate change initiative-abridged report: Islamabad, Pakistan.

12. Ciret C \& Sellers AH (1998). Sensitivity of ecosystem models to the spatial resolution of the NCAR 
Community Climate Model CCM2. Clim Dyn 14: 409-429.

13. Gaffin S, Xing X \& Yetman G (2004). Downscaling and geo-spatial gridding of socio-economic projections from the IPCC Special Report on Emissions Scenarios (SRES). Glob Environ Change 14(2): 105-123.

14. Grotch SL \& Cracken M (1991).The use of general circulation models to predict regional climate change. J Clim 4: 286-303.

15. Hellström C \& Chen D (2003). Statistical downscaling based on dynamically downscaled predictors: application to monthly precipitation in Sweden. Adv Atmos Sci 20(6): 951-958.

16. Linderson ML, Achberger C \& Chen D (2004). Statistical downscaling and scenario construction of precipitation in Scania, southern Sweden. Nord Hydrol 35(3): 261-287.

17. VonStorch H, Zorita E \& Cubash U (1993). Downscaling of global climate change estimates to regional scales: an application to Iberian rainfall in wintertime. J Clim 6: 1161-1671.

18. Busuioc A, Chen D \& Hellström C (2001). Performance of statistical downscaling models in GCM validation and regional climate change estimates: application for Swedish precipitation. Intl J Climatol 21: 557-578.

19. FAO (2015). AQUASTAT: Pakistan. Food and Agriculture Organization, Available at http://www.fao.org/nr/water/aquastat/co untries regions/ $\mathrm{PAK} /$ index.stm.

20. Dost M (2006). Country Pasture/forage Resource Profiles: Pakistan. FAO, Rome.

21. GOP (2010). National rangeland policy, draft. Government of Pakistan, Available at http://waterinfo.net.pk/sites/default/files
/knowledge/National\%20Rangeland\%2 0Policy\%202010\%20-\%20Draft.pdf.

22. Condon M, Kriens D, Lohani A \& Sattar E (2014). Challenge and response in the Indus Basin. Water Policy 16: 5886.

23. Briscoe J \& Qamar U (2005). Pakistan's water economy: Running Dry. World Bank, Washington.

24. Kugelman M (2009). Introduction. Chapter 1 in Running on Empty: Pakistan's Water Crisis. Woodrow Wilson International Center for Scholars, Washington.

25. Immerzeel WW \& Bierkens MFP (2012). Asia's water balance. Nat Geosci 5: 841-842.

26. Lutz AF, Immerzeel WW \& Kraaijenbrink PDA (2014a). Gridded meteorological data sets and hydrological modelling in the Upper Indus Basin. Future Water Report 130.

27. Nepal S \& Shrestha AB (2015). Impact of climate change on the hydrological regime of the Indus, Ganges and Brahmaputra river basins: a review of the literature. Intl J Water Resour Dev 31(2): 201-218.

28. Yu W, Yang YC, Savitsky A, Alford D, Brown C, Wescoat J, Debowicz D \& Robinson S (2013). The Indus Basin of Pakistan: The impacts of climate risks on water and agriculture. World Bank, Washington.

29. Laghari AN, Vanham D \& Rauch W (2012). The Indus basin in the framework of current and future water resources management. Hydrol Earth Syst Sci 16: 1063-1083.

30. Archer DR, Forsythe N, Fowler HJ \& Shah SM (2010). Sustainability of water resources management in the Indus Basin under changing climatic and socioeconomic conditions. Hydrol Earth Syst Sci 14: 1669-1680. 
31. Rodo X (2003). Global climate current research and uncertainties in the climate system. University of Barcelona, Climate Research Group, Barcelona Spain.

32. Hussain A, Zulqarnain $M \&$ Hussain $J$ (2010). Catastrophes in the South Punjab due to climate change and the Role of PIDEANS.

33. Oxfam Report on Climate Change (2011). Six months into the floods resetting Pakistan's priorities through reconstruction. 144 Oxfam Briefing Paper.

34. Quadir DA, Hussain MA \& Hossain MA (2004). The status of climate variation in Pakistan and its impacts. SAARC Meteorological Research Centre (SMRC), Dhaka, Bangladesh.

35. IPCC (2001). Climate change 2001: working group II: impacts, adaptation and vulnerability. Cambridge University Press, New York, USA.

36. Pakistan Country Report (1994). Climate alert, vol 7, no 4, July-August 1994.
37. Parry ML (1978). Climatic change, agriculture and settlements. Dawson Folkestone, UK.

38. Thompson LM (1975). Weather variability, climate change and food production. Sci 188: 534-541.

39. World Meteorological Organization (1979). Proceedings of the world climate conference. WMO, Geneva.

40. Rounsevell MDA, Evans SP \& Bullick $P$ (1999). Climate change and agricultural soils impacts and adaptation. In: IPCC (ed) Climate change 2001: impacts, adaptation and vulnerability, Cambridge University Press, Cambridge, USA, 43: 683-709.

41. Chaudhuri UN, Kirkam MB \& Kanemasu ET (1990). Root growth of winter wheat under elevated carbon dioxide and drought. Crop Sci 30: 853857.

42. Kimball BA, Pinter PJJ, Garcia RL, LaMorte RL, Wall GW, Hunsaker DJ, Wechsung G, Wechsung F \& Kartschall T (1995). Productivity and water use of wheat under free-air $\mathrm{CO}_{2}$ enrichment. Global Change Biol 1: 429-442. 